\title{
Pericardial Synovial Sarcoma: Case Report, Literature Review and Pooled Analysis
}

\author{
JOSE DURAN-MORENO ${ }^{1}$, KATERINA KAMPOLI ${ }^{1}$, EMMANOUIL I. KAPETANAKIS ${ }^{2}$, \\ MARIA MADEMLI ${ }^{3}$, NEKTARIOS KOUFOPOULOS ${ }^{4}$, PERIKLIS G. FOUKAS ${ }^{4}$, \\ KOSTAS KOSTOPANAGIOTOU ${ }^{2}$, PERIKLIS TOMOS ${ }^{2}$ and ANNA KOUMARIANOU ${ }^{1}$ \\ ${ }^{1}$ Hematology Oncology Unit, Fourth Department of Internal Medicine, Attikon University Hospital, \\ National and Kapodistrian University of Athens, Athens, Greece; \\ ${ }^{2}$ Department of Thoracic Surgery, Attikon University Hospital, \\ National and Kapodistrian University of Athens, Athens, Greece; \\ ${ }^{3}$ Second Department of Radiology, Attikon University Hospital, \\ National and Kapodistrian University of Athens, Athens, Greece; \\ ${ }^{4}$ Second Department of Pathology, Attikon University Hospital, \\ National and Kapodistrian University of Athens, Athens, Greece
}

\begin{abstract}
Background: Pericardial synovial sarcomas (PSS) are very rare tumors, with dismal prognosis and limited data. We describe the clinical features and identify prognostic factors of primary PSS. Case Report: We describe the case of a 56-year-old male patient with PSS managed by the multidisciplinary team of thoracic oncology. The therapeutic plan comprised surgery, chemotherapy, stereotactic radiosurgery and targeted therapy, with excellent results. Materials and Methods: Data from 37 cases reported in English during the past 20 years were gathered and analyzed. PSS was found to occur at a mean age of $36 \pm 17.082$ (range $=13-67$ ) years. Survival analysis was performed on 20 cases with follow-up of at least 6 months. Conclusion: Only complete resection of the tumor seems to be an independent prognostic factor. To our knowledge, this is the first report on the safety and effectivity of pazopanib in PSS and may provide guidance for similar cases in the future.
\end{abstract}

Primary tumors of the heart are extremely rare, being 20times less frequent than secondary ones, with a prevalence

This article is freely accessible online.

Correspondence to: Anna Koumarianou, MD, Ph.D., Hematology Oncology Unit, Fourth Department of Internal Medicine, Attikon University Hospital, 1 Rimini street, Haidari, Athens, 124 62, Greece. Tel/Fax: +30 2105831687, Mobile: +30 6932281861, email: akoumari@yahoo.com

Key Words: Pericardial synovial sarcoma, chemotherapy, pazopanib, stereotactic radiosurgery. of $0.02 \%$. Among cardiac sarcomas, pericardial sarcoma is one of the rarest, but its true incidence is unknown (1). Thus, medical experience in pericardial sarcoma is reduced to a handful of cases reported in the literature. The most frequent sarcomas of the pericardium seem to be synovial sarcoma and angiosarcoma (1).

Pericardial sarcomas usually manifest with dyspnea, cough and chest pain due to cardiac failure (1). Occasionally, pericardial effusion or cardiac tamponade may develop (2).

Despite its name, synovial sarcoma is a tumor of uncertain cell origin unrelated to the synovium and, although it arises in most cases from deep soft tissues of the extremities and adjacent to joints or tendons, it can involve any site (3). Histologically, the tumor is composed of epithelial and spindle cells in different proportions, which has resulted in classification of monophasic (only one component exists) and biphasic (both of the components can be found). Given its epithelial and mesenchymal double nature, immunohistochemistry is positive for keratin and epithelial membrane antigen (EMA), as well as for CD99, S-100 protein and BCL2 apoptosis regulator (BCL2), with a wide range of intensities and high intra-tumoral heterogeneity (4). Transducin-like enhancer of split 1 (TLE1) is the most sensitive and specific marker for synovial sarcoma, and helps distinguish it from its histological mimics $(5,6)$. The differential diagnosis includes malignant peripheral nerve sheath tumor, carcinosarcoma, fibrosarcoma and mesothelioma, among other spindle-cell tumors, which are sometimes impossible to distinguish from synovial sarcoma without cytogenetics (7). A cytogenetic analysis with fluorescent in situ hybridization or RT-PCR is used to confirm diagnosis, as the translocation $t(X ; 18)$ (p11;q11), affecting one of the synovial sarcoma-X (SSX) genes 
and the SS18 gene (previously known as SYT), respectively, is present in around $90 \%$ of synovial sarcomas (3).

For diagnosis and staging of the disease, cardiac ultrasound, chest computed tomography and cardiac magnetic resonance imaging (MRI) are recommended (2). Initial surgical resection, with diagnostic and palliative objectives, is usually performed but complete excision is rarely achieved (8). Chemotherapy and radiotherapy, as described in the few cases reported in the literature, may provide a slim benefit in survival. Tyrosine-kinase inhibitors have been part of the therapeutic armamentarium against soft-tissue sarcomas from 2012 (9). To our knowledge, this is the first case of a patient with pericardial synovial sarcoma receiving pazopanib to be reported.

\section{Case Report}

A 56-year-old man with no significant medical history presented with symptoms of dyspnea and fatigue. A chest $\mathrm{x}$ ray demonstrated an increased cardiac shadow. A subsequent cardiac ultrasound identified a large pericardial mass with pericardial effusion, but the ejection fraction was in the normal range at $65 \%$. The electrocardiogram and Holter monitoring indicated a normal rhythm. As shown by a chest computed tomography, the size of the solid lesion was $8.1 \times 5.6 \mathrm{~cm}$, and the location was adjacent to the great vessels of the heart next to the root of the aorta, the pulmonary artery and the superior cava vein, as if originating from the adherent cuff of the pericardium. No associated lymphadenopathy, pulmonary lesions or large vessel infiltration were identified. A cardiac MRI confirmed the presence of a pericardial mass of $7.5 \times 5.5 \times 4 \mathrm{~cm}$, while cardiac and large-vessel infiltration could not be excluded for (Figure 1A).

The case was discussed at the thoracic oncology Multidisciplinary Team meeting, and the surgical option was decided as a first step to attain both diagnostic and possibly therapeutic objectives. However, despite inconclusive findings on the pre-operative assessment, intraoperatively, the mass was found to have infiltrated the aortic root and ascending aorta, and thus excision was incomplete.

Histology showed the tumor to have a biphasic (epithelioid and spindle-cell) morphology (Figure 2A and B). Neoplastic cells were immunopositive for cytokeratin AE1/AE3 (Figure 2C), cytokeratin 7, cytokeratin 19, epithelial membrane antigen, epithelial cell adhesion molecule/epithelial specific antigen BerEp4, vimentin, CD99 (Figure 2D), TLE1 (Figure 2E) and BCL2 (Figure 2F); moreover, the epithelioid constituent was immunopositive for cytokeratin $8 / 18$, as well as containing a few cells with carcinoembryonic antigen immunopositivity in their luminal aspect. Immunopositivity for p53 was found in $20-30 \%$ of tumor cells, whereas the proliferative index (immunostaining with Ki67) was estimated to be in the range of $30 \%$.
Based on the presence of residual disease and the histopathological findings, the Multidisciplinary Team meeting decided for non-cardiotoxic chemotherapy and stereotactic radiosurgery in order to achieve substantial clinical response and improve survival while maintaining a good quality of life. The patient underwent a total of 6 cycles of pegylated liposome-encapsulated doxorubicin $\left(50 \mathrm{mg} / \mathrm{m}^{2}\right)$ at 4-week intervals (10). Re-assessment with cardiac MRI showed a decrease in the size of the lesion (Figure 1B) while positron-emission tomography 3 months later indicated stable disease according to RECIST criteria (11) (Figure 1C). The patient was subsequently submitted to image-guided stereotactic radiosurgery with cyberknife, receiving a total dose of 40 Gy (800 cGy/fraction/day).

After radiation treatment, re-evaluation with cardiac MRI indicated a partial response yet with persistence of residual disease (Figure 1D). The patient was offered second-line therapy with the tyrosine kinase inhibitor pazopanib (800 $\mathrm{mg} /$ day) (9). Since then the patient has continued on the same therapy, on regular follow-up for over 2 years, with MRI showing an excellent response (Figures $1 \mathrm{E}$ and $\mathrm{F}$ ). Following combination therapy with debulking surgery, non-cardiotoxic chemotherapy, stereotactic radiosurgery and tyrosine-kinase inhibitor pazopanib maintenance therapy to the date of preparation of this article, this patient has achieved a survival of 36 months from diagnosis, with no evidence of disease relapse and an excellent quality of life.

\section{Pooled Analysis}

Material and methods. Given the lack of clinical experience reported in the literature, we launched a search on PubMed for synovial sarcoma of the pericardium, which yielded 64 entries from inception to 2018. Criteria for case selection were: English language, histology of synovial sarcoma, and a tumor arising from pericardium. Nine entries were not case reports, two were not reported in English, four were not synovial sarcoma and 17 were tumor of the mediastinum not arising from the pericardium. Finally, 36 cases were selected. Frequencies, means and medians were calculated. Differences in frequencies between groups were compared by Chi-squared or Fisher's exact test (two-tailed). A difference of $p<0.05$ was considered statistically significant. Cases were reported as isolated ones or as a part of a series of pericardial or cardiac sarcomas. Statistical analyses were carried out using a statistical software (SPSS 24.0; IBM, Armonk, NY, USA).

Results. Demographic, clinicopathological, therapeutic and follow-up data were gathered and analyzed from a total of 37 cases (including the present one) (16-46).

According to the analysis of data from these reported cases, it seems that pericardial synovial sarcoma has a clear male 

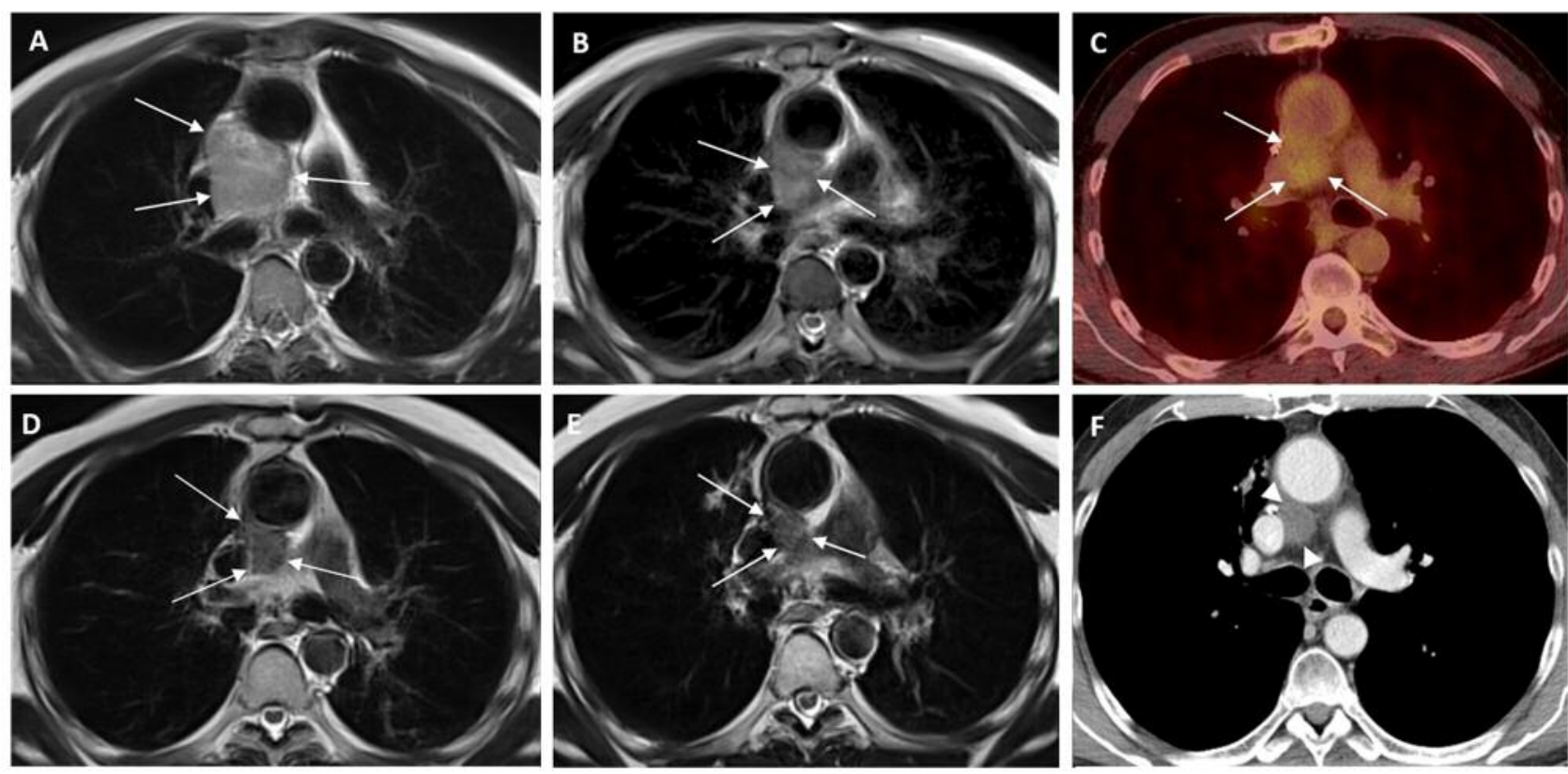

Figure 1. Serial images of pericardial sarcoma according to applied therapies. A: Magnetic resonance imaging (MRI) study of the thorax, T2weighted imaging (T2WI) axial image, at diagnosis, showing an inhomogeneous hyperintense lesion of the mediastinum among the aorta, pulmonary artery, main bronchi and superior vena cava (arrows) B: T2WI axial image at the same level after the fourth chemotherapy session, showing decrease in the size of the lesion. C: Follow-up with positron-emission tomography 3 months later indicated stability of the lesion size with mild hypermetabolic activity (maximum standard uptake value: 3.1) D: T2WI MRI study at the same level after Cyber Knife radiosurgery with further decrease of the size and signal intensity of the tumor. E: Follow-up MRI study T2WI after 5 months of therapy with tyrosine kinase inhibitor pazopanib (Votrient) indicated a further slight decrease of the tumor size. F: Follow-up computed tomography at the same level 4 months later, during therapy with Votrient, showing stability of the tumor size (arrow heads).

predilection, with a male:female ratio of $4.28: 1$. Age at diagnosis ranged from 13 to 67 years, with a mean ( \pm standard deviation) age of presentation of $36 \pm 17.082$ years. The median age was 34 years, with kurtosis value of -1.168 and skewness value of 0.331 , describing an incidence slightly greater in those younger than 30 years. The left atrium appears to be the most frequent location $(38.46 \%)$ and predilection of the atria is clear, with $73.07 \%$ of cases arising from the upper part of the pericardium (Table I). The average tumor size at presentation was $9.75 \pm 3.47 \mathrm{~cm}(5.00-18.00 \mathrm{~cm})$. Presenting symptoms may vary and are shown in Table II, most frequently being dyspnea and cough. For diagnostic purposes, echocardiogram was the first diagnostic test performed in 30 out of the 31 cases $(96.7 \%)$. Completion of diagnosis before any surgical approach (intent for resection or surgical biopsy) with computerized tomography of the chest was performed in $50.0 \%$, and cardiac MRI was added in $34.4 \%$ of the cases. A presurgical diagnostic positron-emission tomography was available for $12.5 \%$.

Among therapeutic options, surgical excision, such as conventional sternotomy and cardiopulmonary bypass, was applied in approximately $83.3 \%$ of cases. However, as
Table I. Anatomic distribution of pericardial sarcoma in patients*.

\begin{tabular}{lccc}
\hline & Atrial & Ventricular & Total \\
\hline Right & 9 & 3 & 12 \\
Left & 10 & 4 & 14 \\
Total & 19 & 7 & 26 \\
\hline
\end{tabular}

*Missing data for 9 patients.

infiltration of surrounding tissues was a common scenario, radical surgery is not always feasible, being successful in a $25.9 \%$ of the cases. Among the seven patients for whom complete resection was reported, adjuvant chemotherapy was administered to four $(57.17 \%)$, and adjuvant radiotherapy to one (14.28\%). Two patients (28.57\%) did not undergo any adjuvant treatment and one of them experienced relapse 7 months after surgery. Histologically, $56.7 \%$ of the reported cases were monophasic synovial sarcomas.

Data regarding chemotherapy and radiotherapy were limited to 31 and 29 , respectively, out of the 37 described cases. Chemotherapy was administered after surgery in 

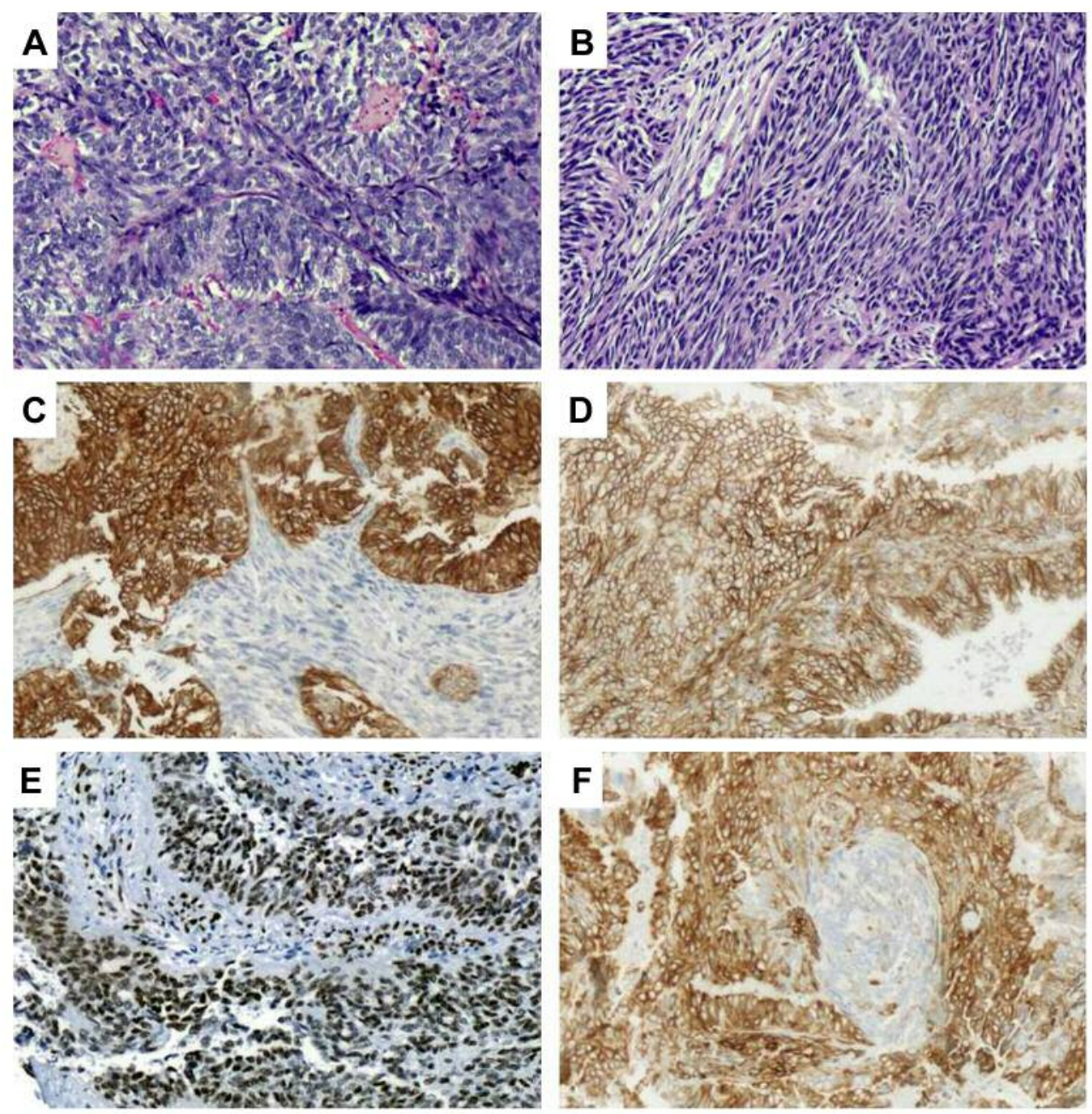

Figure 2. Microscopically, a biphasic morphological pattern was noted for our case, with both an epithelioid (A) as well as a spindle (B) cell component (hematoxylin and eosin). Tumor cells showed immunopositivity for cytokeratins AE1/AE3 (C), CD99 (D), transducin-like enhancer of split $1(E)$ and BCL2 (F). Magnification $\times 20$.

$67.7 \%$ of cases, while adjuvant radiation therapy was applied in $31.0 \%$ of cases. In seven cases out of 29 , neither chemotherapy nor radiotherapy were administered. Reasons for this were: physician's choice $(\mathrm{n}=3)$, poor performance status $(\mathrm{n}=2)$, finding at autopsy $(\mathrm{n}=1)$ and patient's refusal $(\mathrm{n}=1)$. Anthracyclines and ifosfamide were the drugs most used after surgery, in combination $(58.8 \%)$ or monotherapy (11.8\% for each) (Table III).

With five cases lacking follow-up, 32 cases were available for survival analysis. The median follow-up was 18.30 (0$168)$ months. At the time of the report, eight patients were alive without disease, 11 were alive with disease, and $13 \mathrm{had}$ died due to their disease, presenting a median overall survival of 27 (range $=0-168$ ) months. For survival analysis, Kruskal-Wallis test was performed on the 20 cases with follow-up of at least 6 months. Among all the variables, only complete resection seemed to have an independent effect on survival (chi-square 10.510, $\mathrm{p}=0.005$ ) (Table IV).

\section{Discussion}

Synovial sarcoma of the pericardium is a rare neoplasm for which very few data on diagnosis and treatment are available, from few cases reported in the literature. With this small amount of data, we were able to identify a trend in incidence toward male sex and ages between adolescence and early youth. The most common presentation is dyspnea and cough, but a broad range of symptoms have been described. Diagnosis is more often achieved with echocardiogram and CT of the chest. However, a cardiac 
Table II. Clinical presentations of patients with pericardial synovial sarcoma.

\begin{tabular}{llc}
\hline & & $\mathrm{N}(\%)$ \\
\hline Principal symptom* & Dyspnea & $15(44.1)$ \\
& Fatigue & $2(5.9)$ \\
& Cough & $4(11.8)$ \\
& Signs of tamponade & $3(8.8)$ \\
& Dizziness & $1(2.9)$ \\
& Fever & $5(14.7)$ \\
Secondary symptom** & Precordial pain & $4(11.8)$ \\
& Dyspnea & $3(11.5)$ \\
& Fatigue & $4(15.4)$ \\
& Cough & $4(15.4)$ \\
& Signs of tamponade & $5(19.2)$ \\
& Fever & $3(11.5)$ \\
& Precordial pain & $7(26.9)$ \\
\hline
\end{tabular}

Missing data for $* 3$ patients, $* * 11$ patients.
Table III. Reported treatments performed in patients with pericardial synovial sarcoma.

\begin{tabular}{lc}
\hline Treatment & $\mathrm{N}(\%)$ \\
\hline Surgery* & $30(83.3)$ \\
Incomplete resection/surgical biopsy & $20(74.1)$ \\
Complete resection & $7(25.9)$ \\
$\quad$ Adjuvant treatments after complete resection & $5(71.45)$ \\
$\quad$ Chemotherapy & $4(57.17)$ \\
$\quad$ Radiotherapy & $1(14.28)$ \\
Chemotherapy** & $21(67.7)$ \\
Anthracycline & $2(11.8)$ \\
Ifosfamide & $2(11.8)$ \\
Anthracycline + ifosfamide & $10(58.8)$ \\
Other & $3(17.6)$ \\
Radiotherapy*** & $9(31.0)$ \\
\hline
\end{tabular}

Missing data in $* 1$ patient, $* * 6$ patients, $* * * 8$ patients.

Table IV. Association of clinicopathological characteristics with survival in pericardial synovial sarcoma.

\begin{tabular}{|c|c|c|c|c|c|c|}
\hline & & & \multicolumn{3}{|c|}{ Mean for survival time (months) } & \multirow{3}{*}{$p$-Value } \\
\hline & & & \multirow[t]{2}{*}{ Mean } & \multicolumn{2}{|c|}{ 95\% Confidence interval } & \\
\hline & \multicolumn{2}{|c|}{ Subgroup (number of patients)* } & & Lower & Upper & \\
\hline \multirow[t]{2}{*}{ Gender } & Male & 30 & 50.28 & 8.09 & 92.47 & 0.686 \\
\hline & Female & 7 & 22.66 & 14.15 & 31.18 & \\
\hline \multirow[t]{2}{*}{ Age } & $>36$ Years & 17 & 26.36 & 18.77 & 33.95 & 0.964 \\
\hline & $\leq 36$ Years & 20 & 58.73 & 0.00 & 123.4 & \\
\hline \multirow[t]{4}{*}{ Principal symptom } & Dyspnea & 15 & 24.79 & 19.10 & 30.48 & 0.080 \\
\hline & Cough & 4 & 31.00 & 31.00 & 31.00 & \\
\hline & Tamponade & 3 & 78.67 & 0.00 & 166.24 & \\
\hline & Fever & 5 & 14.62 & 0.00 & 30.70 & \\
\hline \multirow[t]{2}{*}{ Tumor diameter } & $\geq 9 \mathrm{~cm}$ & 13 & 21.54 & 12.63 & 30.45 & 0.473 \\
\hline & $<9 \mathrm{~cm}$ & 15 & 25.70 & 19.65 & 31.76 & \\
\hline \multirow[t]{5}{*}{ Location } & Right atrium & 9 & 85.57 & 12.99 & 158.14 & 0.342 \\
\hline & Right ventricle & 3 & 12.25 & 0.00 & 28.35 & \\
\hline & Left atrium & 10 & 8.89 & 6.127 & 11.65 & \\
\hline & Left ventricle & 4 & 28.00 & 28.00 & 28.00 & \\
\hline & Unknown & 9 & 5.019 & 18.31 & 37.98 & \\
\hline \multirow[t]{3}{*}{ Histological subtype } & Monophasic & 17 & 29.04 & 22.96 & 35.12 & 0.256 \\
\hline & Biphasic & 13 & 84.07 & 26.92 & 141.23 & \\
\hline & Unknown & 7 & 8.00 & 3.48 & 12.52 & \\
\hline \multirow{2}{*}{ Surgery } & Yes & 30 & 54.70 & 8.39 & 101.01 & 0.063 \\
\hline & No & 7 & 17.07 & 0.00 & 34.78 & \\
\hline \multirow[t]{2}{*}{ Complete resection } & Yes & 7 & 168.00 & 168.00 & 168.00 & 0.031 \\
\hline & No & 23 & 24.75 & 18.23 & 31.26 & \\
\hline \multirow[t]{2}{*}{ Chemotherapy } & Yes & 20 & 28.97 & 24.17 & 33.77 & 0.382 \\
\hline & No & 9 & 86.54 & 22.45 & 150.63 & \\
\hline \multirow[t]{3}{*}{ Chemotherapy drug } & Ifosfamide & 2 & 29.00 & 27.04 & 30.96 & 0.400 \\
\hline & Anthracycline + ifosfamide & 10 & 29.33 & 21.15 & 37.16 & \\
\hline & Other & 3 & 31.00 & 31.00 & 31.00 & \\
\hline \multirow[t]{2}{*}{ Radiotherapy } & Yes & 9 & 26.71 & 20.30 & 33.13 & 0.518 \\
\hline & No & 20 & 44.62 & 6.72 & 82.52 & \\
\hline
\end{tabular}

*Missing data of follow-up were not considered for this analysis. 
MRI may help surgical planification. The use of positronemission tomography/CT seems of dubious use, as none of the patients presented with metastasis at diagnosis.

Surgical treatment was found to have no impact on overall survival, according to the pooled analysis performed. However, it was the most common initial approach, as was used for biopsy as well as for palliation of symptoms. Of note, only three patients did not undergo surgery and of these, only one was included in the survival analysis, as the other two had died within the first 6 months. Although surgery may have no impact on survival due to the frequent failure of complete resection, complete resection is recommended as it was the only independent prognostic factor associated with survival.

As no guidelines can be applied for this disease, administration of adjuvant chemotherapy and radiotherapy is at the discretion of the doctor as well as the preferences of the patient. This may explain the inconsistency in the application of these therapeutic approaches, with superiority of chemotherapy over radiotherapy. An argumentative basis for this fact lies in the potential cardiotoxicity. It is reasonable to assume that the choice of chemotherapy might be based on the potential cardiotoxicity of these drugs. This is of utmost importance in these patients, who may undergo cardiac surgery and radiotherapy to the heart. Novel agents, such as pegylated liposome-encapsulated doxorubicin, and older drugs such as cyclophosphamide have been associated with reduced cardiotoxicity as compared to doxorubicin and ifosfamide (12).

Radiation therapy for persistent disease after surgery might be difficult due to potential cardiotoxicity. Stereotactic radiosurgery permits the precise administration of high-dose radiation over the tumor, diminishing toxic effects on the surrounding tissues. The benefit of stereotactic radiosurgery with Cyberknife on sarcomas of the heart has been previously reported, although for different cardiac primaries, proving effective in preventing local disease progression (13).

Even if multimodality treatment based on surgery, chemotherapy and radiotherapy is performed, prognosis of pericardial synovial sarcoma remains dismal, with a median overall survival of 27 months shown by the present pooled analysis. These data highlight the urgent need for new, more effective treatments.

Pazopanib is an oral inhibitor of major receptor tyrosine kinases, including vascular endothelial growth factor receptors $1-3$, platelet-derived growth factor receptor-A and c-KIT. It is a well-tolerated drug that achieves a median progression-free survival of 4.6 months as a second-line treatment (9). Among toxicities of pazopanib, cardiotoxicity must be considered in these patients. Nevertheless, long-term experience with this drug supports the administration of pazopanib having minimal cardiac toxic effects (14). Even if literature on pazopanib and cardiac sarcomas is restricted to angiosarcoma, presumably due to its antiangiogenic mechanism of action, a high response rate and long progression-free survival have been reported in synovial sarcoma of other primary sites, representing $16 \%$ of long-term responders (over 2 years of treatment) (15).

\section{Conclusion}

To our knowledge, this is the first report of a patient with pericardial synovial sarcoma treated with multimodality therapy (surgery, chemotherapy, stereotactic radiosurgery and pazopanib), achieving survival of at least 36 months, with an excellent clinical response and quality of life. Given the lack of data on this topic, our pooled analysis encompasses the international experience on pericardial synovial sarcoma, encourages a multidisciplinary approach and adds pazopanib as a safe and potentially effective treatment.

\section{Consent for Publication}

Written informed consent was obtained from the patient for publication of this case report and any accompanying images. A copy of the written consent is available for review by the Editor-inchief of this journal.

\section{Availability of Data and Material}

The datasets used and/or analyzed during the current study are available from the corresponding Author on reasonable request.

\section{Funding}

Funding was received from the Hellenic Study Group of Psychoneuroimmunology in Cancer.

\section{Conflicts of Interest}

The Authors report no conflicts of interest in relation to this article.

\section{Authors' Contributions}

JDM, KK and AK prepared the first draft of the article. EIK and MM produced Figure 2 and Tables. NN and PF produced Figure 1 and histopathological analysis. PT and AK perceived the idea and revised the final article. All Authors read and approved this article.

\section{Acknowledgements}

The Authors are grateful to Professor Ioannis G. Panayiotides for his expert advice during the preparation of the article.

The Authors acknowledge that part of the publication expenses of this article were covered by the Hellenic Study Group of Psychoneuroimmunology in Cancer.

\section{References}

1 Maleszewski JJ and Anavekar NS: Neoplastic pericardial disease. Cardiol Clin 35(4): 589-600, 2017. PMID: 29025549. DOI: $10.1016 /$ j.ccl.2017.07.011 
2 Phatak P, Khanagavi J, Puri S, Aronow WS, Puccio C, Yusuf Y and Puccio C: Pericardial synovial sarcoma: challenges in diagnosis and management. F1000Research 3: 15, 2014. PMID: 24715974. DOI: 10.12688/f1000research.3-15.v1

3 Fletcher CDM, Bridge JA, Hogendoorn P and Mertens F (eds): WHO Classification of Tumours of Soft Tissue and Bone. Fourth Edition. WHO 2013; IARC WHO Classification of Tumours, No 5. ISBN-13 9789283224341.

4 Pollock RE, Karnell LH, Menck HR and Winchester DP: The National Cancer Data Base report on soft tissue sarcoma. Cancer 78(10): 2247-2257, 1996. PMID: 8918421. DOI: 10.1002/(SICI) 1097-0142(19961115)78:10<2247::AID-CNCR29>3.0.CO;2-Y

5 Foo WC, Cruise MW, Wick MR and Hornick JL: Immunohistochemical staining for TLE1 distinguishes synovial sarcoma from histologic mimics. Am J Clin Pathol 135(6): 839844, 2011. PMID: 21571956. DOI: 10.1309/AJCP45SS NAOP XYXU

6 Jagdis A, Rubin BP, Tubbs RR, Pacheco M and Nielsen TO: Prospective evaluation of TLE1 as a diagnostic immunohistochemical marker in synovial sarcoma. Am J Surg Pathol 33(12): 1743-1751, 2009. PMID: 19809272. DOI: 10.1097/PAS.0b013e3181b7ed36

7 Thway K and Fisher C: Synovial sarcoma: Defining features and diagnostic evolution. Ann Diagn Pathol 18(6): 369-380, 2014. PMID: 25438927. DOI: 10.1016/j.anndiagpath.2014.09.002

8 Vega Hernández B, Quintana RB, Méndez RD, Lozano Martínez-Luengas Í, Folgueras Sánchez MV and Silva Guisasola J: Primary Pericardial Synovial Sarcoma. A Clinical Challenge. Rev Esp Cardiol 71(8): 601-692, 2018. DOI: 10.1016/j.recesp. 2017.04.007

9 Van Der Graaf WTA, Blay JY, Chawla SP, Kim DW, BuiNguyen B, Casali PG, Schöffski P, Aglietta M, Staddon AP, Beppu Y, Le Cesne A, Gelderblom H, Judson IR, Araki N, Ouali M, Marreaud S, Hodge R, Dewji MR, Coens C, Demetri GD, Fletcher CD, Dei Tos AP, Hohenberger P, EORTC Soft Tissue and Bone Sarcoma Group and PALETTE study group: Pazopanib for metastatic soft-tissue sarcoma (PALETTE): A randomised, double-blind, placebo-controlled phase 3 trial. Lancet 379(9829): 1879-1886, 2012. PMID: 22595799. DOI: 10.1016/S0140-6736(12)60651-5

10 Judson I, Radford JA, Harris M, Blay JY, van Hoesel Q, le Cesne A, van Oosterom AT, Clemons MJ, Kamby C, Hermans C, Whittaker J, Donato di Paola E, Verweij J and Nielsen S: Randomised phase II trial of pegylated liposomal doxorubicin (DOXIL ${ }^{\circledR} /$ CAELYX $^{\circledR}$ ) versus doxorubicin in the treatment of advanced or metastatic soft tissue sarcoma: A study by the EORTC Soft Tissue and Bone Sarcoma Group. Eur J Cancer 37(7): 870-877, 2001. PMID: 11313175. DOI: 10.1016/S09598049 (01)00050-8

11 Schwartz LH, Seymour L, Litière S, Ford R, Gwyther S, Mandrekar S, Shankar L, Bogaerts J, Chen A, Dancey J, Hayes W, Hodi FS, Hoekstra OS, Huang EP, Lin N, Liu Y, Therasse P, Wolchok JD and de Vries E: RECIST 1.1 - Standardisation and disease-specific adaptations: Perspectives from the RECIST Working Group. Eur J Cancer 62: 138-145, 2016. PMID: 27237360. DOI: 10.1016/j.ejca.2016.03.082

12 Savani M, Murugan P and Skubitz KM: Long-term cure of soft tissue sarcoma with pegylated-liposomal doxorubicin after doxorubicin and ifosfamide failure. Clin Sarcoma Res 9: 1, 2019. PMID: 30651969. DOI: 10.1186/s13569-018-0111-0
13 Bonomo P, Cipressi S, Desideri I, Masi L, Doro R, Iermano C, Greto D, Simontacchi G, Mangoni M, Paiar F, Meattini I, Scoccianti S, Santoro G, Valente S, Gensini GF and Livi L: Stereotactic body radiotherapy with CyberKnife for cardiac malignancies. Tumori 101(3): 294-297, 2015. PMID: 25908042. DOI: $10.5301 / \mathrm{tj} .5000280$

14 Pinkhas D, Ho T and Smith S: Assessment of pazopanib-related hypertension, cardiac dysfunction and identification of clinical risk factors for their development. Cardio-Oncology 3: pii: 5, 2017. PMID: 29497565. DOI: 10.1186/s40959-017-0024-8

15 Kasper B, Sleijfer S, Litière S, Marreaud S, Verweij J, Hodge RA, Bauer S, Kerst JM and van der Graaf WT: Long-term responders and survivors on pazopanib for advanced soft tissue sarcomas: Subanalysis of two European Organisation for Research and Treatment of Cancer (EORTC) clinical trials 62043 and 62072. Ann Oncol 25(3): 719-724, 2014. PMID: 24504442. DOI: $10.1093 /$ annonc/mdt586

16 Coli A, Chiariello GA, Novello M, Colizzi C and Massetti M: Treatment of cardiac synovial sarcoma: Experience of two cases. J Cardiothorac Surg 13(1): 84, 2018. PMID: 29970129. DOI: 10.1186/s13019-018-0771-0

17 Khan HR, Ansari MI, Thain AP, Abdullah S, Parasa R and Varcoe RW: Mediastinal monophasic synovial sarcoma with pericardial extension causing hemodynamic instability. Oxf Med Case Rep 2018(5): omy017, 2018. PMID: 29765618. DOI: 10.1093/omcr/omy017

18 Liu E, Chen Z, Lian Z, Liu C, Xie Q, Wang S and Wang S: Giant primary pericardial synovial sarcoma in an adolescent with cardiac tamponade: Contrast-enhanced CT and ${ }^{18} \mathrm{~F}-\mathrm{FDG}$ PET/CT findings. J Nucl Cardiol, 2018. PMID: 30088197. DOI: 10.1007/s12350-018-1396-3

19 de Oliveira DCL, Pacheco EO, Lopes LTR, do Carmo CC and de Melo ASA: Pericardial synovial sarcoma: radiological findings. Radiol Bras 51(3): 201-202, 2018. PMID: 29991844. DOI: $10.1590 / 0100-3984.2016 .0200$

20 Jain AS, Simon S, Muthukrishnan I, Gambhir A and Patil S: Pericardial synovial sarcoma followed up with contrast-enhanced PET-CT: Clin Nucl Med 42(4): 315-318, 2017. PMID: 28195904. DOI: 10.1097/RLU.0000000000001574.

$21 \mathrm{Yu} \mathrm{L}$ and Gu T: Giant pericardial synovial sarcoma. J Card Surg 32(4): 266-267, 2017. PMID: 28326619. DOI: 10.1111/jocs.13121.

22 Youn HC, Lee Y and Kim SC: Pericardial synovial sarcoma presenting with large recurrent pericardial effusion. J Thorac Dis 8(6): E412-416, 2016. PMID: 27293869. DOI: 10.21037/ jtd.2016.04.57

23 Muramatsu T, Takeshita S, Tanaka Y, Morooka H, Higure R and Shiono M: Primary pericardial synovial sarcoma. J Thorac Dis 7(10): E496-498, 2015. PMID: 26623128. DOI: 10.3978/ j.issn.2072-1439.2015.10.19

24 Goldblatt J, Saxena P, McGiffin DC and Zimmet A: Pericardial synovial sarcoma: A rare clinical entity. J Card Surg 30(11): 801804, 2015. PMID: 26347295. DOI: 10.1111/jocs.12609

25 Ozmen E, Kayadibi Y, Samanci C, Ustundag N, Ozdemir G, Adaletli I and Kurugoglou S: Primary Pericardial Synovial Sarcoma in an Adolescent Patient: Magnetic Resonance and Diffusion-weighted Imaging Features. J Pediatr Hematol Oncol 37(4): e230-233, 2015. PMID: 25647483. DOI: 10.1097/MPH. 0000000000000305

26 Ohzeki M, Fujita S, Miyazaki H, Morita H, Kanki S, Ozawa H, Katsumata T, Kurisu Y, Tsuji M, Tanigawa J, Sohmiya K, Hoshiga 
$\mathrm{M}$ and Ishizaka N: A Patient with primary pericardial synovial sarcoma who presented with cardiac tamponade: A case report and review of the literature. Intern Med 53(6): 595-601, 2014. PMID: 24633030. DOI: 10.2169/internalmedicine.53.1749.

27 Bezerra SG, Brandão AA, Albuquerque DC, Militão RC, Hadlich MS and Azevedo CF: Pericardial synovial sarcoma: case report and literature review. Arq Bras Cardiol 101(6): e103-106, 2013. PMID: 24522279. DOI: 10.5935/abc.20130235

28 Chekrine T, Sahraoui S, Cherkaoui S, Eddakkaoui H, Labsaili H, Marouane S, El Attar H, Zamiati S, Mehadji BE and Benider A: Primary pericardial synovial sarcoma: A case report and literature review. J Cardiol Cases 9(1): 40-43, 2013. PMID: 30546781. DOI: 10.1016/j.jccase.2013.09.005

29 Yoshino M, Sekine Y, Koh E, Kume Y, Saito H, Kimura S, Hamada $\mathrm{H}, \mathrm{Wu} \mathrm{D}$ and Hiroshima K: Pericardial synovial sarcoma: a case report and review of the literature. Surg Today 44(11): 2167-2173, 2014. PMID: 24022581. DOI: 10.1007/ s00595-013-0720-4

$30 \mathrm{Wu}$ X, Chen R and Zhao B: Pericardial synovial sarcoma in a dyspnoeic female with tuberculous pericarditis: A case report. Oncol Lett 5(6): 1973-1975, 2013. PMID: 23833678. DOI: 10.3892/ol.2013.1279

31 Kodikara S: Pericardium: An exceedingly rare site for a primary biphasic synovial sarcoma. Indian J Pathol Microbiol 55(2): 227229, 2012. PMID: 22771650. DOI: 10.4103/0377-4929.97884

32 Cheng Y, Sheng W, Zhou X and Wang J: Pericardial synovial sarcoma, a potential for misdiagnosis: Clinicopathologic and molecular cytogenetic analysis of three cases with literature review. Am J Clin Pathol 137(1): 142-149, 2012. PMID: 22180488. DOI: 10.1309/AJCP34ZVFLAUTMGL

33 Myers PO, Konstantinidis S, Karatzas N, Milas F and Panos A: Pericardial synovial sarcoma of the heart; Is it always worth operating? J Cardiovasc Surg 52(5): 749-751, 2011. PMID: 21894142

34 Yokouchi Y, Hiruta N, Oharaseki T, Ihara F, Oda Y, Ito S, Yamashita H, Ozaki S, Gomi $\mathrm{T}$ and Takahashi K: Primary cardiac synovial sarcoma: A case report and literature review. Pathol Int 61(3): 150-155, 2011. PMID: 21355957. DOI: 10.1111/j.1440-1827.2010.02631.x

35 Akerström F, Santos B, Alguacil AM, Orradre JL, Lima P and Zapardiel S: Pericardial synovial sarcoma. Thorac Cardiovasc Surg 59(3): 175-177, 2011. PMID: 21480141. DOI: 10.1055/s0030-1250336

36 Moorjani N, Peebles C, Gallagher P and Tsang G: Pericardial synovial sarcoma. J Card Surg 24(3): 349-351, 2009. DOI: 10.1111/j.1540-8191.2009.00827.x
37 Fatimi SH and Saleem T: Giant synovial cell sarcoma of the thorax in a 46-year-old man: A case report. Cases J 24(3): 349351, 2009. PMID: 19438797. DOI: $10.1186 / 1757-1626-2-9324$

38 Zhang PJ, Brooks JS, Goldblum JR, Yoder B, Seethala R, Pawel B, Gorman JH, Gorman RC, Huang JH, Acker M and Narula N: Primary cardiac sarcomas: a clinicopathologic analysis of a series with follow-up information in 17 patients and emphasis on long-term survival. Hum Pathol 39(9): 1385-1395, 2008. PMID: 18602663. DOI: 10.1016/j.humpath.2008.01.019

39 Hing SN, Marshall L, Al-Saadi R and Hargrave D: Primary pericardial synovial sarcoma confirmed by molecular genetic studies: A case report. J Pediatr Hematol Oncol 29(7): 492-495, 2007. PMID: 17609629. DOI: 10.1097/MPH.0b013e3180640d2e

40 Schumann C, Kunze M, Kochs M, Hombach V and Rasche V: Pericardial synovial sarcoma mimicking pericarditis in findings of cardiac magnetic resonance imaging. Int J Cardiol 118(3): e83-84, 2007. PMID: 17399807. DOI: 10.1016/j.ijcard.2007. 01.029

41 Van Der Mieren G, Willems S, Sciot R, Dumez H, Van Oosterom A, Flameng W and Herijgers P: Pericardial synovial sarcoma: 14-Year survival with multimodality therapy. Ann Thorac Surg 78(3): e41-42, 2004. PMID: 15337081. DOI: 10.1016/j.athoracsur.2004.02.011

42 Yano M, Toyooka S, Tsukuda K, Dote H, Morimoto Y, Ohata N, Ichimura K, Aoe M, Date H and Shimizu N: SYT-SSX fusion genes in synovial sarcoma of the thorax. Lung Cancer 44(3): 391397, 2004. PMID: 15140553. DOI: 10.1016/j.lungcan.2003. 11.011

43 Anand AK, Khanna A, Sinha SK, Mukherjee U, Walia JS and Singh AN: Pericardial synovial sarcoma. Clin Oncol 15(4): 186488, 2003. PMID: 12846496. DOI: 10.1016/S0936-6555 (02)00215-7

44 Trupiano JK, Rice TW, Herzog K, Barr FG, Shipley J, Fisher C and Goldblum JR: Mediastinal synovial sarcoma: Report of two cases with molecular genetic analysis. Ann Thorac Surg 73(2): 628-630, 2002. PMID: 11845884. DOI: 10.1016/S0003-4975 (01)03110-1

45 Oizumi S, Igarashi K, Takenaka T, Yamashiro K, Hiraga H, Fujino T and Horimoto M: Primary pericardial synovial sarcoma with detection of the chimeric transcript SYT-SSX: Jpn Circ J 63(4): 330-332, 1999. PMID: 10475786.

46 Al-Rajhi N, Husain S, Coupland R, McNamee C and Jha N: Primary pericardial synovial sarcoma: a case report and literature review. J Surg Oncol 70(3): 194-198, 1999. PMID: 10102352.

Received May 29, 2019

Revised July 1, 2019

Accepted July 8, 2019 